\author{
Cadernos de \\ ESTUDOS LINGUISTTICOS - (58.2), Campinas, pp. 257-276 - mai./ago. 2016
}

\title{
FORMAS TRATAMENTAIS EM CARTAS \\ BAIANAS: SUJEITO E OUTRAS FUNÇÕES ${ }^{1}$
}

\author{
AROLDO LEAL DE ANDRADE ${ }^{2}$ \\ ZENAIDE DE OLIVEIRA NOVAES CARNEIRO ${ }^{3}$ \\ MARIANA FAGUNDES DE OLIVEIRA LACERDA ${ }^{4}$
}

\begin{abstract}
RESUMO: Apresentam-se, neste trabalho, dados diacrônicos do sistema de tratamento do português baiano, na posição de sujeito e complemento, com o objetivo maior de contribuir para o estudo da configuração diatópico-diacrônica desse sistema no português brasileiro. O corpus de pesquisa é constituído por cartas de remetentes baianos dos séculos XIX e XX. Os dados extraídos das cartas foram analisados de acordo com os princípios da Sociolinguística Quantitativa, com o apoio do software Goldvarb X. Entre os resultados para a função de sujeito, observou-se uso significativo de formas de tratamento nominais, como o senhor, Vossa Excelência e Vossa Senhoria. Não houve dados de $t u$ e vós expressos, mas em alguns casos o verbo estava flexionado nas formas correspondentes, ficando o sujeito nulo. A forma você começa a aparecer em sua forma plena no século XX, e o uso de Vosmecê ocorre de forma mais efetiva durante o século XIX, diminuindo com o tempo. Na função de complemento acusativo, a estratégia mais produtiva é lhe, com $39 \%$, ficando a forma tradicional de acusativo o/a com $36 \%$. A forma dativa predominante é também o clítico lhe, com $63 \%$, ficando a forma te com meros $2 \%$. Notou-se que a variação se concentrou nos dados de remetentes que apresentavam uso exclusivo de você na posição de sujeito. Num aspecto geral, os resultados corroboram um sistema de formas de tratamento com alguns traços importantes de conservadorismo linguístico, em comparação com dados de outros estados brasileiros, como Pernambuco, Rio Grande do Norte e Rio de Janeiro.
\end{abstract}

Palavras-chave: Sistema de Tratamento. Cartas Baianas. Séculos XIX e XX.

ABSTRACT: In this work we present diachronic data on the system of forms of address in subject

${ }^{1}$ Uma versão prévia deste texto foi apresentada no I Simpósio do LaborHistórico: história dos pronomes de tratamento no português brasileiro, realizado em março de 2015, no Rio de Janeiro. Os autores agradecem pelas sugestões recebidas nessa oportunidade, assim como aos pareceristas e editores da Cadernos de Estudos Linguísticos. Este trabalho se relaciona ao projeto temático Fapesp "A língua portuguesa no tempo e no espaço: contato linguístico, gramáticas em competição e mudança paramétrica" (nr. 2012/06078-9) e o projeto Fapesb "Corpus Eletrônico de Documentos Históricos do Sertão (nr. 5566/2010) e CNPq "Vozes do Sertão em Dados: história, povos e formação do português brasileiro" (nr. 401433/2009-9). Eventuais erros remanescentes são da responsabilidade dos autores.

\footnotetext{
22aroldo.andrade@gmail.com

${ }^{3}$ zenaide.novais@gmail.com

4marianafag@gmail.com
} 
position, in the variety of Portuguese written in Bahia, with the aim of contributing to the study of the diatopic-diachronic configuration of this system in Brazilian Portuguese. The research corpus is composed of letters written by Bahian writers from the $19^{\text {th }}$ and $20^{\text {th }}$ centuries. The data extracted from the letters were analyzed according to the principles of Quantitative Sociolinguistics, with the help of the Goldvarb $X$ software. Among the obtained results for the subject function, there was significant use of nominal forms of address, such as o senhor ('Mister'), or Vossa Excelencia ('Your Excellency') and Vossa Senhoria ('Mister/Madam'). There was no data of $t u$ ( $2^{\text {nd }}$ person singular) and vós ( $2^{\text {nd }}$ person plural), but in some cases the verb is inflected for the corresponding forms, with the null subject. The form voce ( $3^{\text {rd }}$ person singular) appears in its full form in the $20^{\text {th }}$ century, and the use of Vosmecê ('Your Mercy') occurs more effectively during the $19^{\text {th }}$ century, decreasing with the time. In accusative complement function, the most productive strategy is lhe, with $39 \%$, leaving the traditional accusative form $o / a$ with $36 \%$. The predominant dative form is also the clitic lhe, with $63 \%$, the form te keeping the level of $2 \%$. We have noted that the variation focused on data from senders who had exclusive use of você in subject position. In a general aspect, the results confirm a system of address forms with some important traits of linguistic conservatism, compared to data from other Brazilian States, such as Pernambuco, Rio Grande do Norte and Rio de Janeiro.

Keywords: System of address forms. Bahian letters. $19^{\text {th }}$ and $20^{\text {th }}$ centuries.

\section{INTRODUÇÃO}

O objetivo central deste texto é contribuir com os estudos que buscam compor um quadro da configuração diatópico-diacrônica do sistema de tratamento do português brasileiro (PB), trazendo, especificamente, dados de cartas escritas por baianos, disponibilizadas no Corpus Eletrônico de Documentos Históricos do Sertão (CE-DOHS). A hipótese de partida é que diferentes regiões do Brasil possam adotar sistemas tratamentais diferentes, o que pode explicar discrepâncias na evolução histórica dessas formas de tratamento encontradas na Bahia, face aos resultados obtidos para outras regiões do país.

Apresentam-se, inicialmente, as questões teórico-metodológicas que norteiam o trabalho e, em seguida, a documentação epistolar analisada e o perfil dos remetentes. Posto isso, são descritos os dados de sujeito e complemento obtidos na pesquisa e feitas as considerações sobre as formas tratamentais do português na Bahia.

\section{DESCRIÇÃO DO CORPUS DE BASE DA PESQUISA}

O trabalho de pesquisa baseou-se numa amostra de 379 cartas, presentes em diferentes subcorpora, conforme distribuição apresentada na tabela a seguir. As referidas cartas estão digitalizadas na versão XML, com uso da ferramenta eDictor, e encontram-se on-line no site do CE-DOHS (CARNEIRO \& OLIVEIRA, 2011), que faz parte do Corpus Compartilhado do projeto PHPB (PHPB 2013). 
Cadernos de ESTUDOS LINGUIISTICOS (58.2) - mai./ago. 2016

Tabela 1. Composição da amostra de cartas de remetentes baianos.

\begin{tabular}{|c|c|c|}
\hline Década & Subcorpus de cartas & Quantidade de cartas \\
\hline $1809-1850$ & Cartas para Vários Destinatários & 7 \\
\hline 1860 & Cartas para Vários Destinatários & 17 \\
\hline 1870 & Cartas para Vários Destinatários & 10 \\
\hline 1880 & $\begin{array}{c}\text { Cartas para Cícero Dantas Martins, } \\
\text { Barão de Jeremoabo }\end{array}$ & 16 \\
\hline 1890 & $\begin{array}{l}\text { Cartas para Cícero Dantas Martins, Barão de } \\
\text { Jeremoabo }\end{array}$ & 150 \\
\hline 1900 & $\begin{array}{c}\text { Cartas para Cícero Dantas Martins, Barão } \\
\text { de Jeremoabo Cartas para Severino Vieira, } \\
\text { Governador da Bahia }\end{array}$ & 71 \\
\hline 1910 & $\begin{array}{c}\text { Cartas Baianas: o acervo de João da Costa Pinto } \\
\text { Victoria }\end{array}$ & 08 \\
\hline 1920 & $\begin{array}{c}\text { Cartas Baianas: o acervo de João da Costa Pinto } \\
\text { Victoria Cartas do Acervo Dantas Jr. }\end{array}$ & 19 \\
\hline 1930 & Cartas do Acervo Dantas Jr. & 37 \\
\hline 1940 & Cartas do Acervo Dantas Jr. & 17 \\
\hline 1950 & Cartas do Acervo Dantas Jr. & 11 \\
\hline 1960 & Cartas do Acervo Dantas Jr. & 3 \\
\hline 1970 & Acervo da Família Oliveira & 2 \\
\hline 1980 & $\begin{array}{c}\text { Correspondências Amigas, o acervo de Valente, } \\
\text { Bahia }\end{array}$ & 11 \\
\hline 1990 & $\begin{array}{c}\text { Correspondências Amigas, o acervo de Valente, } \\
\text { Bahia }\end{array}$ & 5 \\
\hline Total & & 379 \\
\hline
\end{tabular}

Para este trabalho, foi composto um subcorpus de 379 cartas, extraídas dos seguintes acervos dos séculos XIX e XX, integrantes da coleção denominada Cartas Brasileiras, que reúne 943 cartas, escritas por 217 remetentes do século XIX, entre os quais há 89 baianos, e 158 remetentes do século XX, entre os quais há 101 baianos. Como o critério para a definição da base de dados é a naturalidade dos remetentes, e não o local de escrita das cartas, foram selecionadas, de diversos acervos, as cartas escritas por baianos nos séculos XIX e XX, como será explicitado adiante. Os acervos também foram definidos com base no grau de escolaridade dos remetentes em três grandes grupos (CARNEIRO, 2005):

1. Grau superior (nível universitário, incluindo cursos em escolas militares e em seminários religiosos): variante culta.

2. Grau intermediário (até aulas maiores): variante semiculta.

3. Grau primário (de primeiras letras até o $5^{\circ}$ ano): variante não culta. 
Cabe salientar que as cartas do século XIX foram numeradas progressivamente, como parte de um único conjunto, de 1 a 500: acervo Cartas para vários destinatários, com cartas numeradas de 1 a 208; acervo Severino Vieira, com cartas numeradas de 209 a 310; e acervo Cícero Dantas Martins, com cartas numeradas de 311 a 500. Além do acesso via internet, o material também está disponível em papel e em CD-ROM, respectivamente em Carneiro (2005: volume 2) e Carneiro (2011, volume 1). Já os acervos do século XX foram numerados separadamente, e também estão disponíveis em Carneiro (2011: volumes 2 e 3).

Como já observado, as cartas utilizadas nas amostras constituem a produção escrita de pessoas ilustres, cultas e citadinas, com alto grau de escolaridade e letramento, e de pessoas semicultas, de áreas rurais da Bahia; há também dados de populares (chamados aqui de não cultos, como é o caso, por exemplo, de sete vaqueiros das fazendas do Barão de Jeremoabo). Essa informação é importante para justificar o padrão predominantemente regular dos usos linguísticos identificados com relação às formas tratamentais.

No conjunto de cartas de escreventes ilustres, também são encontradas correspondências de familiares e amigos; por essa razão, por exemplo, mesmo exercendo cargos públicos (remetentes e destinatário), como é o caso do acervo Cartas para Severino Vieira, então governador da Bahia. Esses escreventes consideram seu destinatário como amigo. As cartas do referido acervo foram guardadas em uma gaveta especial no gabinete do governador, não entrando na documentação oficial de circulação pública; trata-se do que chamamos de cartas particulares em circulação excepcional, em espaço privado-público. Tais cartas ampliam a margem de verificação de contextos de variação das formas tratamentais tu e você, se comparadas às cartas puramente oficiais.

\section{PRINCÍPIOS TEÓRICO-METODOLÓGICOS}

Os dados foram analisados de acordo com os princípios da Sociolinguística Quantitativa (LABOV, 1994), com apoio do software Goldvarb X. Para tanto, os dados foram classificados quanto à variável dependente (paradigma de tratamento), e quanto a onze variáveis independentes: forma concreta realizada; função sintática (incluindo a realização do sujeito: pleno vs. nulo); padrão de organização sintática (estrutura argumental do verbo); tratamento na posição de sujeito e de complemento; gênero do remetente; faixa etária do remetente; período de escrita da carta; parentesco dos missivistas; subgênero da carta particular (pessoal, familiar, ou amorosa); norma linguística do remetente (culto, semiculto e não culto).

É importante salientar que foram incluídos os dados em que o interlocutor faz referência à 2. ${ }^{\text {a }}$ pessoa do singular, conjunto em que se inserem formas de tratamento nominais (Vossa Senhoria, Vossa Mercê, Vossa Excelência), pronominais $\left(t u\right.$, você) e nulas, identificáveis pela flexão verbal em $2 .^{\mathrm{a}}$ ou $3 .^{\mathrm{a}}$ pessoa (falas, fala) ou não identificáveis por estar o verbo numa forma nominal. As formas imperativas não foram contabilizadas. 
Cadernos de ESTUDOS LINGUÍSTICOS (58.2) - mai./ago. 2016

Em alguns casos, os escreventes utilizaram a forma $V$, que pode ser ambígua entre vosmecê e você; porém, se o mesmo escrevente não utilizou claramente a forma você, consideramos a primeira forma como não marcada.

Para a análise dos dados, partimos das reflexões de Lopes \& Cavalcante (2011) a respeito da presença de dois subsistemas de representação da segunda pessoa do singular no português brasileiro (PB), considerando interações entre o sistema pronominal e suas formas nominais de origem com outras características do sistema gramatical em questão, como a perda de sujeitos nulos.

Além disso, levamos em consideração, de maneira acessória, a Teoria da Polidez de Brown \& Levinson (1987), para quem se deve levar em conta a preservação da face entre os interactantes. Nesse sentido, o uso social que se faz das formas de tratamento parece ter uma relevância crucial, e a classificação da relação entre os missivistas a partir da classificação de seu parentesco foi feita com base na relação entre poder e solidariedade, conforme proposto em Brown \& Gilman (1960).

\section{DESCRIÇÃO DA VARIAÇÃO I: FORMAS TRATAMENTAIS NA FUNÇÃO DE SUJEITO}

Foram identificados 739 dados de formas de tratamento relativas à 2. ${ }^{a}$ pessoa do singular na posição de sujeito na documentação epistolar analisada. Antes de passar à análise quantitativa propriamente dita, tecemos algumas observações gerais sobre a distribuição das formas de tratamento na base de dados, em comparação com o observado em outros estados do País (LOPES et al., 2015) e da região Nordeste (MARTINS et al., 2015).

Observou-se na amostra uma quantidade significativa de formas de tratamento nominais, entre as quais as mais numerosas são Vossa Excelência e Vosmecê, o que pode indicar uma maior formalidade entre os interlocutores, e especialmente, uma posição hierarquicamente superior do destinatário face ao remetente, identificada a partir do perfil dos escreventes, como se vê nos seguintes exemplos:

(1) Satisfazendo com muito prazer ao pedido que Vossa Excelência fez me em sua carta de 14 do corrente, relativo ao Senhor Carlos José Botelho...

[Acervo Cartas para Vários Destinatários, Carta 106 - 19 de maio de 1875 - De Visconde de Caravelas para Conselheiro Martim Francisco]

(2) ... espero que Vossa Senhoria o remunere como merece, pois nesta terra de calmas e lamas, todo o serviço he penoso.

[Acervo Cartas para Vários Destinatários, Carta 4 - 9 de julho de 1810 - De José da Silva Lisboa para Manoel Ignacio da Cunha e Menezes]

Relativamente a isso, o uso de vosmecê, forma nominal que precedeu você, ocorre de forma mais frequente em dados do século XIX, sendo frequentemente abreviada $(V$.), como no original do exemplo (3), ou apagada, como no exemplo (4): 
ANDRADE, CARNEIRO \& LACERDA - Formas tratamentais em cartas baianas: sujeito e ...

(3) O Doutor Ananias disse aqui na Bahia a um amigo nosso, que Vosmecê entendia que a estrada de ferro do Timbó era livre para todos.

[Acervo Cartas para Cícero Dantas Martins, Carta 367 - 18 de dezembro de 1894 - De Benício Penalva de Faria para o Barão de Jeremoabo]

(4) Estimo a continuação de sua vigorosa saude, de minha Excelentissima Comadre e Thotonio, com quem receberá minhas visitas.

[Acervo Cartas para Cícero Dantas Martins, Carta 372 - 12 de fevereiro de 1897 - De Benício Penalva de Faria para o Barão de Jeremoabo]

Tais estratégias para evitar o uso da forma plena Vosmecê demonstram incerteza na estratégia de polidez por parte do missivista Benício Penalva, que utilizava de maneira sistemática a forma Vossa Excelência alguns anos antes:

(5) Tenho implorado A Vossa Excelência sua proteção e de sua Excelentissima familia...

[Acervo Cartas para Cícero Dantas Martins, Carta 364 - 11 de fevereiro de 1891 - De Benício Penalva de Faria para o Barão de Jeremoabo]

No aspecto diacrônico, as várias formas tratamentais apresentam usos distintos ao longo do tempo. Por exemplo, a forma o senhor (a senhora) era corrente mesmo no contexto familiar, na relação entre membros mais jovens da família face aos mais velhos: ${ }^{5}$

(6) ... acho que é um ato de humanidade e de confiança que a senhora deposita em minha pessoa.

[Acervo Família Oliveira, Carta 23 - 8 de abril de 1973 - De João Carvalho de Matos para sua comadre]

Outro aspecto de mudança diz respeito à forma plena você, que começa a aparecer de maneira não ambígua no século $\mathrm{XX}$, sendo uma das primeiras ocorrências a que se mostra no exemplo abaixo:

(7) Como chegou você a esse "retiro saudoso", como o chama Flávio?

[Acervo Cartas Baianas, Carta 219 - 31 de julho de 1921 - De Maria Luisa Wanderlei de Carvalho Pinho para Yoyô]

Finalmente, a forma nula de 2. ${ }^{a}$ pessoa do plural é mais especificamente utilizada no século XIX, e em contextos formais. Mais uma vez, isso pode incluir o contexto familiar, como na comunicação de filha para pai (Maria Augusta Ferrão de Argolo, de cerca de 21 anos, a Alexandre Gomes Ferrão Argollo, o Barão de Cajaíba). Em tais cartas, Maria Augusta se identifica como "Vossa filha e amiga fiel até o tumulo"; é dela também o exemplo que se mostra abaixo:

\footnotetext{
${ }^{5}$ Esse aspecto provavelmente diferencia a Bahia de outros estados. Considera-se falta de respeito usar a forma você no tratamento de filho com seu pai ou mãe, o que se estende a outros membros mais 
(8) Por Pompilio escrevi-vos hontem, e mandei tudo quanto pedisteis.

[Acervo Cartas para Vários Destinatários, Carta 110 - 31 de maio de 1866 - De

Maria Augusta para seu pai]

Passamos agora à descrição quantitativa da variação em quatro subseções abaixo, relativas aos resultados de alguns grupos de fatores mais relevantes: a sua forma de realização (plena ou nula); a norma linguística dos remetentes; a relação entre os missivistas; e a distribuição diacrônica das formas, em que se apresentam tabulações cruzadas com outros grupos de fatores.

\subsection{A realização do sujeito e as formas de tratamento concretas}

A Tabela 2 apresenta um detalhamento das formas tratamentais em função de sujeito, sejam elas nominais, pronominais ou nulas.

Tabela 2. Distribuição geral das formas de tratamento na função de sujeito.

\begin{tabular}{lcc}
\hline Forma/ distribuição & $\mathbf{N}$ & $\mathbf{\%}$ \\
\hline Nulo:3.sg & 254 & 34,4 \\
\hline Vossa Excelência & 167 & 22,6 \\
\hline Você & 117 & 16,0 \\
\hline Vosmecê & 87 & 11,6 \\
\hline Nulo: sem pessoa & 54 & 7,3 \\
\hline Nulo:2.pl & 17 & 2,3 \\
\hline O senhor & 17 & 2,3 \\
\hline Vossa Senhoria & 13 & 1,8 \\
\hline Nulo:2.sg & 13 & 1,8 \\
\hline TOTAL & $\mathbf{7 3 9}$ & $\mathbf{1 0 0 \%}$ \\
\hline
\end{tabular}

Como era esperado, a forma nula de $3 .^{\text {a }}$ pessoa é a mais frequente, em $34,4 \%$ dos casos, o que pode explicar o fato de poder substituir você, assim como todas as formas nominais. É significativo que as formas de 2. ${ }^{a}$ pessoa do singular $(1,8 \%)$ e do plural $(2,3 \%)$ ocorriam somente em formas nulas. Esse aspecto é relevante, pois o uso de sujeitos nulos diminui no português brasileiro desde o fim do século XIX.

Entre as formas expressas, Vossa Excelência é a mais frequente, com 22,6\% dos casos, seguida pela forma você, que ocorre em $16 \%$ dos casos. Vosmecê ocorre em 11,6\% dos casos, o senhor com 2,3\% e Vossa Senhoria com 1,8\% dos dados. Em parte, essa distribuição se explica em termos da relação de compadrio existente entre vários dos interlocutores.

Para melhor estudar a distribuição das formas tratamentais é preciso deixar de lado as formas nulas não identificáveis (54 ocorrências) e classificar as formas nulas de acordo com sua referência a diferentes formas nominais, como se apresenta na Tabela 3 . 
ANDRADE, CARNEIRO \& LACERDA - Formas tratamentais em cartas baianas: sujeito e ...

Tabela 3. Distribuição das formas de tratamento quanto à realização do sujeito.

\begin{tabular}{lccccc}
\hline Paradigma/ expressão & \multicolumn{2}{c}{ Pleno } & \multicolumn{2}{c}{ Nulo } & Total \\
\hline Vossa Excelência etc. & 197 & $63 \%$ & 114 & $37 \%$ & 311 \\
\hline Você & 117 & $64 \%$ & 67 & $36 \%$ & 184 \\
\hline Vosmecê etc. & 87 & $54 \%$ & 73 & $46 \%$ & 160 \\
\hline Vós & -- & $0 \%$ & 17 & $100 \%$ & 17 \\
\hline$T u$ & -- & $0 \%$ & 13 & $100 \%$ & 13 \\
\hline
\end{tabular}

Nos dados, formas nominais desenvolvidas, tais como Vossa Excelência, Vossa Senhoria e o senhor são as mais frequentes. Logo após, a forma você foi a mais frequente, seguida da forma nominal reduzida Vosmecê (cuja contraparte desenvolvida Vossa Mercê não foi encontrada). Vale ressaltar que a distinção entre formas nulas de você e vosmecê pode ter um grau considerável de erro, já que o apagamento é utilizado por alguns escreventes de forma sistemática, não sendo possível interpretar que forma o escrevente tinha em mente. Finalmente, identificamse as formas nulas correspondentes a vós e tu, cuja distinção mútua é claramente vinculada ao distanciamento entre os missivistas. Diga-se de passagem, a forma de 2. ${ }^{a}$ pessoa do plural foi por vezes utilizada em referência a formas nominais, por desconhecimento da regra de concordância padrão, como no exemplo a seguir:

(9) Esta, excelentíssimo Senhor, tem por fim pedir-vos encarecidamente que acceitais a minha colaboração...

[Acervo Cartas para Severino Vieira, Governador da Bahia, Carta 216 - 5 de outubro de 1901 - De Anna Theophila Filgueiras Autran]

No que tange às formas de 2. ${ }^{a}$ pessoa do singular, elas são em geral usadas de forma consistente, quando o sujeito é assim marcado, sem mistura de formas de tratamento com formas em outras funções gramaticais, por parte dos remetentes cultos e semicultos, exceto no que diz respeito às formas do imperativo:

(10) Se tiveres alguma pista, ligue para mim 940-6872, aguardo-te.

[Acervo Correspondências Amigas, Carta 75 - 13 de maio de 1990 - De Rosimária L. Lima para Adelmário Carneiro Araújo]

É importante salientar que a forma plena tu é inexistente nos dados, aspecto que difere os dados históricos da Bahia dos encontrados em outros estados do Brasil, e mesmo os do Nordeste (cf. MARTINS et al. 2015). ${ }^{6}$

jovens da família face aos mais velhos.

${ }^{6}$ Em outras cartas, que não fizeram parte deste estudo, encontraram-se mais alguns dados de $t u$ expresso, na correspondência trocada entre remetentes cultos do fim do século XIX (CARVALHO JÚNIOR, 2000) e em cartas de inábeis da segunda metade do século XX (SANTIAGO, 2012):

(i) Até o fim do corrente devo tomar posse, e $t u$ não me negarás a justiça de crer que, nesta conjuntura, nada darme-á prazer maior do que o teu apoio, que solicito com todo empenho de nossa amizade nunca interrompida. [Carta de José Gonçalves da Silva ao barão de Jeremoabo. Piabas, 22 de outubro de 1890.]

(ii) Aceite lembarnça minha i de todos meus enviando lembarnça a pitanga i a ana e a Augusto i a P pedirnho i $t u$ da um abarço ni ana 2 bejinho ni Antonio i 4 ni idebarndo. [Carta de Filomena Pereira da Silva para a amiga 


\subsection{A norma linguística dos remetentes}

A classificação dos dados, por ter sido feita levando em consideração um levantamento de dados sociohistóricos acerca de seus remetentes, permitiu sua classificação entre cultos, semicultos e não cultos. No caso das cartas escritas no século XIX, essa separação se reflete no local onde habitam tais remetentes, sendo aqueles provenientes da costa mais cultos que os provenientes do interior. Nossa expectativa era de que houvesse uma influência desse grupo de fatores sobre a variação entre as formas tratamentais.

Para mostrar essa correlação, elencam-se os resultados dessa variável independente face aos paradigmas de formas de tratamento na Tabela 4, excetuando-se os dados de formas nulas não identificáveis.

Tabela 4. Distribuição das formas de tratamento quanto à norma linguística dos remetentes.

\begin{tabular}{lccccccc}
\hline Paradigma/norma & \multicolumn{2}{c}{ Cultos } & \multicolumn{2}{c}{ Semicultos } & Não cultos & Total \\
\hline Vossa Excelência etc. & 86 & $27 \%$ & 193 & $62 \%$ & 32 & $10 \%$ & 311 \\
\hline Você & 44 & $24 \%$ & 43 & $23 \%$ & 97 & $53 \%$ & 184 \\
\hline Vosmecê etc. & 47 & $30 \%$ & 113 & $70 \%$ & -- & $0 \%$ & 160 \\
\hline Vós & 14 & $82 \%$ & 3 & $18 \%$ & -- & $0 \%$ & 17 \\
\hline Tu & 8 & $62 \%$ & 1 & $8 \%$ & 4 & $30 \%$ & 13 \\
\hline
\end{tabular}

Os resultados demonstram que os dados de formas nominais são mais utilizados primeiramente, por semicultos (62\% para formas desenvolvidas e $70 \%$ para formas reduzidas) e, em segundo lugar, por cultos (27\% e $30 \%$, respectivamente). Isso reflete meramente o trânsito social dos missivistas, já que os remetentes semicultos normalmente estão em relação assimétrica face a seus destinatários. Por outro lado, os dados de você são mais frequentes entre os não cultos, correspondendo a mais da metade (53\%) da amostra relevante. Não houve dados de vosmecê e de vós (isto é, de verbo na 2. ${ }^{\mathrm{a}}$ pessoa do plural) entre os não cultos. Finalmente, a maioria dos dados de tu (isto é, de verbo na 2. ${ }^{\text {a }}$ pessoa do singular) ocorreu entre as cartas enviadas por remetentes cultos.

\subsection{A relação entre os missivistas}

Segundo nossos princípios teóricos, a relação entre os missivistas deve ser levada em consideração na descrição da variação, sendo que sua análise pode ser feita a partir da Teoria da Polidez, aliada à dicotomia entre poder e solidariedade (BROWN \& GILMAN, 1960). Assim, foram agrupadas as relações de acordo com a presença ou não de simetria na relação entre os missivistas e, no caso de assimetria, a sua natureza entre ascendente ou descendente. Em cada uma, as relações estabelecidas foram consideradas como mais ou menos solidárias, sendo 
ANDRADE, CARNEIRO \& LACERDA - Formas tratamentais em cartas baianas: sujeito e ... aquelas correspondentes às relações familiares mais próximas, e estas relativas às relações familiares mais distantes ou menos privadas. ${ }^{7}$ Os resultados dessa variável são apresentados na Tabela 5.

Tabela 5. Distribuição das formas de tratamento quanto à relação entre os missivistas.

\begin{tabular}{lccccccccccc}
\hline Relação/ paradigma & \multicolumn{2}{c}{ Vossa Ex. } & \multicolumn{2}{c}{ Você } & \multicolumn{2}{c}{ Vosmecê } & Vós & \multicolumn{2}{c}{ Tu } & Total \\
\hline Simétrica [+sol.] & -- & $0 \%$ & 110 & $98 \%$ & -- & $0 \%$ & -- & $0 \%$ & 2 & $2 \%$ & 112 \\
\hline Simétrica [-sol.] & 309 & $57 \%$ & 69 & $13 \%$ & 153 & $28 \%$ & 8 & $1 \%$ & 6 & $1 \%$ & 545 \\
\hline Assimétrica $\downarrow[+$ sol.] & -- & $0 \%$ & 21 & $100 \%$ & -- & $0 \%$ & -- & $0 \%$ & -- & $0 \%$ & 21 \\
\hline Assimétrica $\downarrow[-$-sol.] & -- & $0 \%$ & 2 & $10 \%$ & 18 & $90 \%$ & -- & $0 \%$ & -- & $0 \%$ & 20 \\
\hline Assimétrica $\uparrow[+$ sol.] & -- & $0 \%$ & 1 & $5 \%$ & 3 & $16 \%$ & 10 & $52 \%$ & 5 & $26 \%$ & 19 \\
\hline Assimétrica $\uparrow[-$ sol.] & 21 & $95 \%$ & -- & $0 \%$ & 1 & $5 \%$ & -- & $0 \%$ & -- & $0 \%$ & 22 \\
\hline
\end{tabular}

Como se nota nessa tabela, o uso de Vossa Excelência é típico de relações com o traço [-solidário] em poder simétrico ou assimétrico ascendente; Vosmecê, por outro lado, é encontrado em relações com o traço [-solidário] de todos os tipos, assim como a relação assimétrica ascendente [+solidário]. A forma você é encontrada em quase todos os tipos de relação, sendo porém quase inexistente naquelas de poder assimétrico ascendente. Finalmente, o uso da forma nula correspondente a $t u$ se pauta por uma proximidade maior, ou mesmo uma grande intimidade entre os interlocutores: frequentemente entre amigos, às vezes entre cônjuges, namorados e irmãos, e raramente na relação mãe $\rightarrow$ filho.

\subsection{A distribuição diacrônica das formas tratamentais}

Esta seção tem por objetivo relacionar a variação e a mudança no uso de diferentes formas tratamentais. Apesar de uma parte da mudança verificada se dever à diferente distribuição das relações entre os missivistas no eixo do tempo, alguns padrões mais gerais podem, outrossim, ser percebidos, como a expansão da forma você. A distribuição diacrônica geral é apresentada na Figura 1 abaixo, com os dados agrupados por trintênios, exceto no último período, em que há um quarentênio (arredondou-se o início do primeiro período para 1810, em vez de 1809).

Amerinda. Fazenda Carrancudo, 25 de maio de 1956]

${ }^{7}$ Para obter essa tabela, realizamos agrupamentos entre os seguintes fatores do grupo relação entre os missivistas:

(i) relações simétricas [+solidárias]: irmãos, cônjuges ou namorados;

(ii) relações simétricas [-solidárias]: primos ou amigos;

(iii) relações assimétricas descendentes [+solidárias]: mãe $\rightarrow$ filho; tio $\rightarrow$ sobrinho;

(iv) relações assimétricas descendentes [-solidárias]: patrão $\rightarrow$ empregado;

(v) relações assimétricas ascendentes [+solidárias]: filha $\rightarrow$ pai; sobrinho $\rightarrow$ tio;

(vi) relações assimétricas ascendentes [-solidárias]: afilhado $\rightarrow$ padrinho; empregado $\rightarrow$ patrão. 


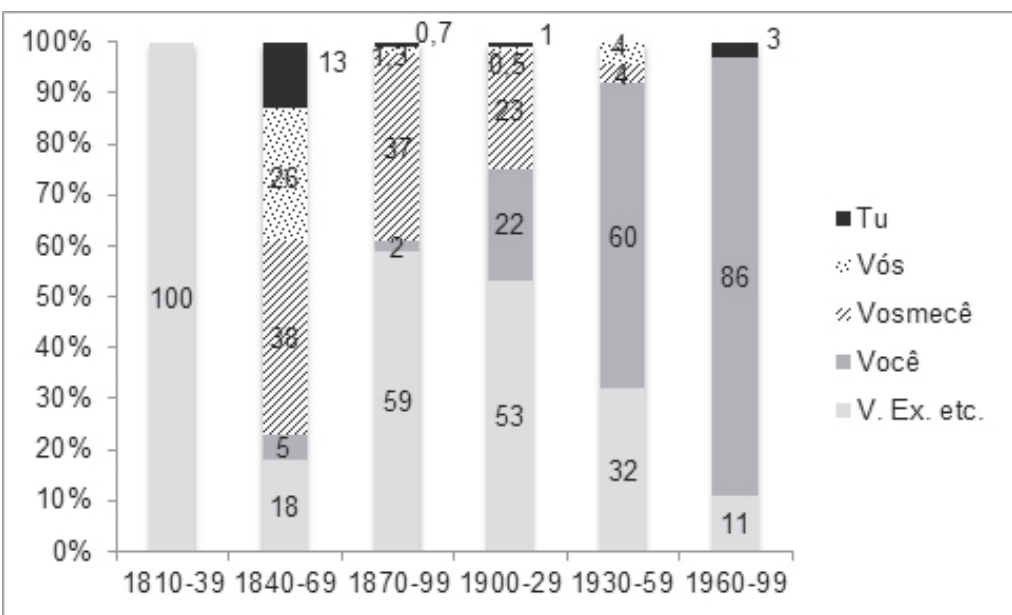

Figura 1. Distribuição diacrônica das formas de tratamento na função de sujeito.

Para a correta interpretação dessa tabela, relembramos que o elemento $V$. Ex. etc. inclui todas as formas de tratamento nominais desenvolvidas. Nota-se que, no primeiro trintênio, só se encontram tais tipos de dados. No segundo e terceiro trintênios, as formas se repartem entre os cinco paradigmas, havendo poucos dados de você (e todos correspondendo a formas nulas). No século XX, a participação dessa forma de tratamento se expande gradativamente, de forma inversamente proporcional aos dados de Vossa Excelência (e demais formas) e de Vosmecê. Os dados de tu (sempre nulo) alcançam o maior percentual (13\%) no trintênio 1840-69, aparecendo de forma tímida durante o século XX, e desaparecendo no trintênio 1930-69. Os dados de vós (sempre nulo) apresentam processo semelhante.

Em seguida, apresentamos um cruzamento entre os dados de $3 .^{\text {a }}$ pessoa do singular nula, variando com as formas nominais de tratamento e com a forma pronominal você, no eixo diacrônico. A Figura 2 demonstra que os dados de sujeitos nulos repercutem um diminuição geral ocorrida no português brasileiro, exceto no último período, em que há uma leve recuperação, retomando valores parecidos aos encontrados no primeiro trintênio do século $\mathrm{XX}^{8}{ }^{8}$

${ }^{4}$ Os dados relativos ao primeiro trintênio do século XIX são muito poucos (seis no total), e expressam tão somente formas nominais, razão pela qual não são representativos; porém, para garantir a comparação com a Figura 1, eles foram mantidos. 


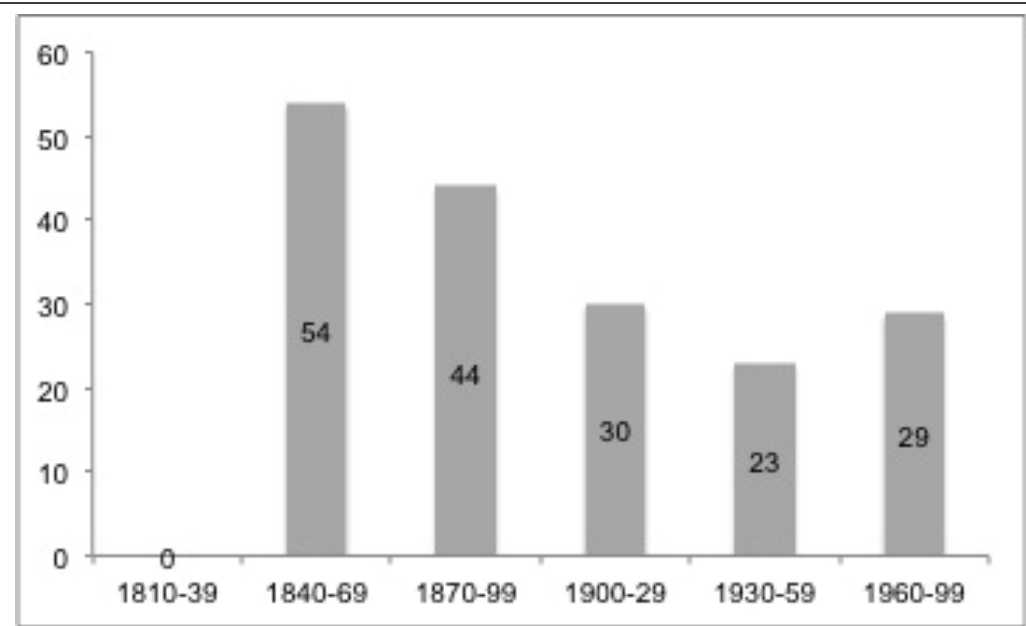

Figura 2. Distribuição diacrônica de sujeitos nulos de 3 . $^{\mathrm{a}}$ pessoa.

Concluímos com esses dados nossas observações sobre as formas tratamentais em função de sujeito, uma vez que um estudo diacrônico relativo à relação entre os missivistas não se mostra muito útil, pela pequena quantidade de dados após sua repartição entre os períodos históricos. Outras variáveis sociais codificadas não estiveram bem distribuídas no tempo, de tal forma que também não apresentamos os resultados respectivos, inclusive a que se refere à norma linguística dos remetentes.

É importante notar alguns sinais de conservadorismo na amostra estudada. Uma breve comparação com dados de Pernambuco e do Rio Grande do Norte (cf. MARTINS et al., 2015) demonstram que a participação de tu é mais limitada que nesses outros estados nordestinos, e sempre feita por meio do uso de sujeitos nulos na amostra analisada. Além disso, o grande número de formas de tratamento nominais no século XIX é semelhante ao encontrado no material analisado em Marcotulio (2010), escrito na segunda metade do século XVIII.

\section{DESCRIÇÃO DA VARIAÇÃO II: AS FORMAS TRATAMENTAIS EM FUNÇÃO DE COMPLEMENTO}

Adotamos neste trabalho a terminologia para os complementos verbais de 2. ${ }^{a}$ pessoa seguindo a terminologia linguística indicativa de casos gramaticais (sem querer, no entanto, sugerir que eles sejam visíveis na língua): acusativo para objeto direto, dativo para objeto indireto que possa ser precedido pela preposição a ou que corresponda à forma de 2. ${ }^{a}$ pessoa no paradigma que inclui o clítico lhe, e oblíquo para objeto indireto que não admite cliticização.

Nas subseções abaixo, analisamos os resultados gerais para cada uma das funções, com análise complementar levando em consideração os grupos de fatores tratamento na posição de sujeito e complemento e período diacrônico. É importante observar que as formas zero (complementos não realizados) não foram contabilizadas. 


\subsection{Formas acusativas}

$\mathrm{Na}$ amostra de cartas em tela foram encontradas as diversas formas marcando o acusativo arroladas na Tabela 6. Aqui é importante lembrar da ocorrência de casos de objeto direto preposicionado.

Tabela 6. Distribuição de formas de tratamento na função acusativa.

\begin{tabular}{lcc}
\hline Forma/ distribuição & $\mathbf{N}$ & $\mathbf{\%}$ \\
\hline lhe & 53 & 39,2 \\
\hline o, $a$ & 48 & 35,5 \\
\hline vos & 11 & 8,1 \\
\hline te & 7 & 5,1 \\
\hline Vossa Excelência & 4 & 2,9 \\
\hline a Vossa Senhoria & 3 & 2,2 \\
\hline você & 2 & 1,4 \\
\hline O senhor & 1 & 0,7 \\
\hline Vosmecê & 1 & 0,7 \\
\hline a vosmecê & 1 & 0,7 \\
\hline a Vossa Excelência & 1 & 0,7 \\
\hline TOTAL & $\mathbf{1 3 5}$ & $\mathbf{1 0 0 \%}$ \\
\hline
\end{tabular}

Como mostrado na tabela acima, a estratégia mais produtiva para a função acusativa foi o the (antiga forma de $3 .^{\text {a }}$ pessoa dativa), com $39 \%$, seguido pelo clítico também de 3. pessoa (o, a), com $35 \%$. As formas te e vos ocorreram em menor percentual, entre $5 \%$ e $8 \%$, ficando você e as formas nominais (precedidas ou não da preposição a) com percentuais em torno de 1\% cada uma. Alguns exemplos são apresentados abaixo:

(11) a. Vóvó as tias e Armando abraçam-lhe...

[Acervo Cartas Baianas, Carta 26 - 24 de abril de 1914 - De Aracy

Leonardo Pereira a seu padrinho]

b. Abraço-te...

[Acervo Severino Vieira, Carta 286 - 8 de março de 1902 - De Pedro Leão Velloso Filho a Severino Vieira]

c. ... eu que vos, conheço desde sua infancia...

[Acervo Cícero Dantas Martins, Carta 425 - 9 de julho de 1901 - De João Martins dos Reis a Cícero Dantas Martins]

d. Eu achei você uma pessoa porreta.

[Acervo Correspondências Amigas, Carta 31 - 20 de outubro de 1980 - De Elzinete Carneiro Magalhães para Adelmário Carneiro Araújo] 
ANDRADE, CARNEIRO \& LACERDA - Formas tratamentais em cartas baianas: sujeito e ...

e. Em primeiro lugar comprimento a Vossa Excelência, e Excelentissima senhora... [Acervo Cícero Dantas Martins, Carta 398 - 5 de dezembro de 1896 - De Domingos Victor de Jesus a Cícero Dantas Martins]

\subsection{Formas dativas}

A Tabela 7 apresenta os resultados de formas tratamentais em função dativa. De maneira geral, as formas acompanham o tratamento empregado na posição de sujeito. O percentual de lhe foi o mais alto, e várias outras estratégias associadas a paradigmas ligados à $3 .^{\text {a }}$ pessoa ocorrem de forma produtiva.

Tabela 7. Distribuição de formas de tratamento na função dativa.

\begin{tabular}{lcc}
\hline Forma/ distribuição & $\mathbf{N}$ & $\mathbf{\%}$ \\
\hline lhe & 448 & 63,5 \\
\hline a Vossa Excelência & 104 & 14,8 \\
\hline vos & 54 & 7,6 \\
\hline te & 15 & 2,1 \\
\hline a Vossa Senhoria & 10 & 1,4 \\
\hline a vosmecê & 7 & 1,0 \\
\hline para você & 2 & 0,2 \\
\hline a si & 1 & 0,1 \\
\hline ola $(s)$ & 1 & 0,1 \\
\hline TOTAL & $\mathbf{1 3 5}$ & $\mathbf{1 0 0} \%$ \\
\hline
\end{tabular}

Os dados repetem a preferência pela forma lhe, que já era a preferida mesmo na função de acusativo, porém, de maneira ainda mais forte, com cerca de $63 \%$, o que não é de surpreender, dada a grande ocorrência de formas nominais. Os demais dados incluem formas nominais precedidas pela preposição $a$, além de vos com cerca de $7 \%$ e te com cerca de $2 \%$. Considerando a pequena porcentagem de sujeitos marcados em 2. ${ }^{a}$ pessoa do plural, é interessante que o dativo seja um nicho de permanência dessa forma arcaizante. As sentenças abaixo ilustram as principais formas encontradas:

(12) a. ... que incluso the remetto os recibos provisorios...

[Acervo Cartas para Dantas Jr., Carta 9 - 13 de fevereiro de 1935 - De Aloysio Lopes de Carvalho Filho a Dantas Jr.]

b. ...venho pela presente agradecer a Vossa Excelência o favor...

[Acervo Cartas para Dantas Jr., Carta 15 - 23 de junho de 1934 - De Altamirano de Carvalho a Dantas Jr.]

c. Desejo-vos o milhor bem na vida extensivo.

[Acervo Cartas para Dantas Jr., Carta 20 - 2 de março de 1939 - De Antidio Reis para Dantas Junior] 
d. Desejo-te boa saude e a todos os teus.

[Acervo Cartas para vários destinatários, Carta 102 - 19 de setembro de 1878 - De F. M. Alvares d'Araújo a Martim Francisco]

O conservadorismo do tratamento nas cartas baianas também se evidencia pela presença de um dado de a si, que apresenta uso regular no português europeu, em referência à 2 . $^{\mathrm{a}}$ pessoa:

(13) ... dezejo morrer sem mais cuidados alem da Familia pois somentes dou um vocto a si. [Acervo Cartas para Cícero Dantas Martins, Carta 347 - 19 de junho de 1903 - De Antônio Ferreira para o Barão de Jeremoabo]

Finalmente, um exemplo encontrado em correspondência de remetente não culto demonstrou o uso de forma privativa do acusativo em função dativa, como se mostra na sentença abaixo:

(14) Por que não me escreveu, se quizesse que eu $o$ escrevesse?

[Acervo Correspondências Amigas, Carta 77 - 10 de janeiro de 1980 - De Valdecy Lopes Carneiro para Adelmário Carneiro Araújo]

\subsection{Formas oblíquas}

As formas de tratamento em função oblíqua são arroladas na Tabela 8. Nelas, nota-se a total inexistência de formas de 2 . $^{\text {a }}$ pessoa do singular.

Tabela 8. Distribuição de formas de tratamento na função oblíqua.

\begin{tabular}{lcc}
\hline Forma/ distribuição & N & \% \\
\hline Prep + V. Ex. etc. & 12 & 42,8 \\
\hline Prep + você & 8 & 28,5 \\
\hline Prep + vosmecê & 6 & 21,4 \\
\hline consigo & 2 & 7,1 \\
\hline TOTAL & $\mathbf{2 8}$ & $\mathbf{1 0 0 \%}$ \\
\hline
\end{tabular}

Nessa função gramatical, as formas nominais desenvolvidas precedidas por uma preposição foram as mais frequentes (44\%), seguidas por você precedido de preposição, e por vosmecê precedido por preposição. Além disso, houve dois casos de consigo:

(15) a. reclamo de Vossa Senhoria, um pouco das relações de amizade valiosa [Acervo Cartas para vários destinatários, Carta 167 - 19 de maio de 1883 - De Vicente Ferreira de Souza a Frederico Lisboa]

b. A' dias fiz uma carta ao Dr. Tota pedindo-lhe que tivesse com Você um intendimento relativamente a sertos acontecimentos.

[Acervo Cartas para Dantas Jr., Carta 34 - 28 de setembro de 1933 - D e Bento Nolasco de Carvalho para Herminio Reis Silva] 
ANDRADE, CARNEIRO \& LACERDA - Formas tratamentais em cartas baianas: sujeito e ...

c. Sobre isso tenho muito que conversar com Vosmice.

[Acervo Cartas para Vários Destinatários, Carta 126 - 27 de setembro de 1883 - De Marcolino de Moura e Albuquerque para Exupério inheiro Canguçu]

d. ... expondo-lhes o meu desejo e decizão firme de collaborar consigo e com elle em política.

[Acervo Cartas para Dantas Jr., Carta 35 - 25 de novembro de 1933 - de Bento Nolasco de Carvalho para Pinto Dantas Junior]

\subsection{Formas de acusativo e dativo: análise complementar}

Procedemos à comparação entre as variadas formas de tratamento em torno de cruzamentos de dados face ao grupo de fatores forma concreta realizada com o grupo de fatores tratamento na posição de sujeito e complemento e com o período de escrita da carta.

A observação do tratamento na posição de sujeito e complemento permite estudar a questão da mistura de paradigmas. Assim, quando o pronome sujeito era do paradigma de $t u$, o emprego de te acusativo ou dativo foi categórico nas cartas. Se o remetente utilizava o paradigma de você, houve a coexistência com formas como te e vos, com o predomínio do uso das formas do paradigma de você, tanto no acusativo como no dativo:

(16) ... você me considero como amigo eu te considero em dobro.

[Acervo Correspondências Amigas, Carta 31 - 20 de outubro de 1980 - De Elzinete Carneiro Magalhães para Adelmário Carneiro Araújo]

(17) ... se você quer mesmo ficar comigo eu ti digo uma coisa...

[Acervo Correspondências Amigas, Carta 32 - 23 de outubro de 1980 - De Erivan Dias Magalhães para Adelmário Carneiro Araújo]

Tais fatos são demonstrados na Tabela 9 abaixo, em que se faz o cruzamento entre o tratamento na posição de sujeito e as formas de acusativo, e na Tabela 10, com levantamento semelhante para as formas de dativo.

Tabela 9. Complementos acusativos face ao tratamento na posição de sujeito.

\begin{tabular}{cccccccc}
\hline Trat./Forma & $\boldsymbol{v o s}$ & $\boldsymbol{t e}$ & $\boldsymbol{v o c} \hat{\boldsymbol{e}}$ & $\boldsymbol{l h e}$ & $\boldsymbol{o} / \boldsymbol{a}$ & $\boldsymbol{s e}$ & $(\boldsymbol{a})$ vosmece \\
\hline $\mathrm{Tu}$ & & $04 / 04$ & -- & -- & -- & -- & \\
excl. & & $100 \%$ & & & & & \\
\hline Você & $01 / 45$ & $02 / 45$ & $01 / 45$ & $21 / 45$ & $16 / 45$ & $02 / 45$ & $02 / 45$ \\
excl. & $2 \%$ & $4 \%$ & $2 \%$ & $46 \%$ & $35 \%$ & $4 \%$ & $4 \%$ \\
\hline
\end{tabular}


Cadernos de ESTUDOS LINGUIISTICOS (58.2) - mai./ago. 2016

Tabela 10. Complementos dativos face ao tratamento na posição de sujeito.

\begin{tabular}{cccccccc}
\hline Trat./Forma & vos & te & $\begin{array}{c}\text { a/para } \\
\text { você }\end{array}$ & lhe & o/a & $\begin{array}{c}\boldsymbol{a} \boldsymbol{V} \text {. Ex./ } \\
\boldsymbol{a o} \boldsymbol{S r} .\end{array}$ & a vosmecê \\
\hline $\mathrm{Tu}$ & -- & $07 / 07$ & -- & -- & -- & -- & -- \\
excl. & & $100 \%$ & & & & & \\
\hline Você & $02 / 146$ & $04 / 146$ & $01 / 49$ & $130 / 146$ & $01 / 146$ & $03 / 146$ & $02 / 146$ \\
excl. & $1 \%$ & $3 \%$ & $0,5 \%$ & $89 \%$ & $0,5 \%$ & $2 \%$ & $1 \%$ \\
\hline Tu/ & -- & $\mathbf{0 4 / 0 4}$ & -- & -- & -- & -- & - \\
Você & & $\mathbf{1 0 0 \%}$ & & & & & \\
\hline
\end{tabular}

As duas tabelas ilustram a observação feita acima, no sentido de mostrar que a variação se concentra nos dados de remetentes que utilizaram exclusivamente a forma você na posição de sujeito. Nos dados de dativo, houve remetentes com variação entre $t u$ e você, e nesses só a forma te ocorreu. Isso pode indicar que, para tais remetentes, há uma total neutralização entre 2 a $^{\mathrm{a}}$ e 3 . $^{\mathrm{a}}$ pessoas.

A seguir apresentamos dados diacrônicos das formas de acusativo e dativo. Mais uma vez, por serem os dados de complemento oblíquo muito limitados, eles não foram utilizados nessa etapa. A Figura 3 demonstra que a variação entre $o / a$ e lhe na função de acusativo é permanente, só não ocorrendo no trintênio 1840-69, quando, em vez deles, ocorre vos. Os dados de te acusativo são irregulares, fortalecendo-se no último período; da mesma forma, você acusativo só ocorre no último período estudado. Lembramos que nessa figura, "FN" indica todas as formas nominais, inclusive vosmecê.

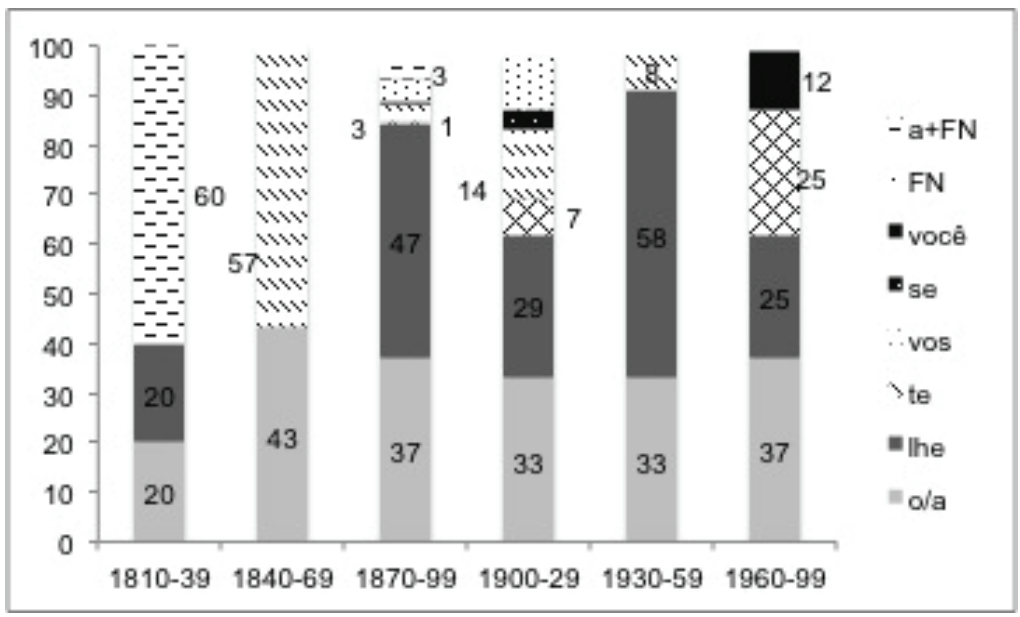

Figura 3. Distribuição diacrônica das formas de tratamento de complemento acusativo.

Finalmente, apresentamos na Figura 4, os dados diacrônicos referentes aos complementos dativos. 


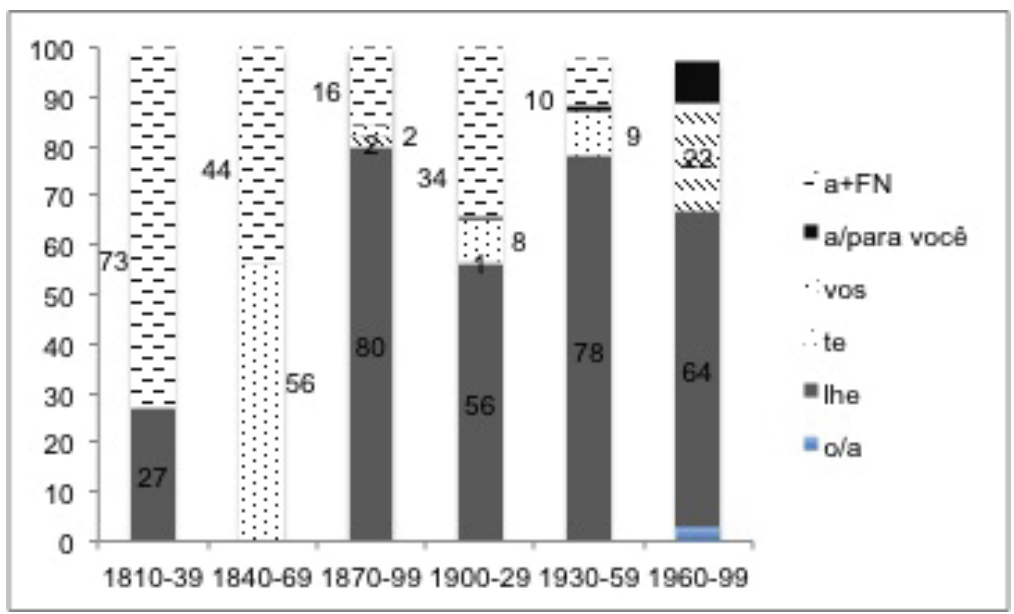

Figura 4. Distribuição diacrônica das formas de tratamento de complemento dativo.

Nesses dados, chama a atenção a ocorrência de te (22\%) e de a/para você ( $8 \%$ ) no último período estudado. Nos períodos anteriores, os dados de lhe variam com as formas nominais e com vos, exceto no segundo trintênio, em que lhe não aparece.

Em comparação com dados epistolares do mesmo período produzidos no estado do Rio de Janeiro (cf. LOPES \& CAVALCANTE, 2011), nota-se que nesse estado os dados de lhe como acusativo são inexistentes e, como dativo, limitam-se a 13\%. Em parte, isso pode ser atribuído à constituição do corpus de cartas da Bahia, que envolvem figuras eminentes e relações de compadrio. Acreditamos, no entanto, que a explicação para a disparidade entre os dois estados não pode se limitar a isso, já que, mesmo nos dados de remetentes não cultos, a forma lhe se generalizou.

\section{CONSIDERAÇÕES FINAIS}

Neste trabalho, descrevemos a variação em formas de tratamento numa amostra diacrônica de cartas baianas dos séculos XIX e XX.

Quanto aos dados em posição de sujeito, observou-se uso significativo de formas de tratamento nominais, como o senhor, Vossa Excelência e Vossa Senhoria. Não houve dados de $t u$ e vós expressos, mas, em alguns casos, o verbo estava flexionado nas formas correspondentes, ficando o sujeito nulo. A forma você começa a aparecer em sua forma plena no século XX. Finalmente, o uso de Vosmecê ocorre de forma mais efetiva nos dados do século XIX, diminuindo com o tempo. O cruzamento com a variável relação entre os missivistas mostrou que Vossa Excelência, Vosmecê e você são formas que demonstram tratamento gradativamente mais amplo, no que se refere aos traços ligados ao poder e solidariedade. Além disso, o uso de $t u$ se pauta por uma grande intimidade entre os interlocutores. No que se refere à realização do sujeito, notou-se uma tendência crescente pelo uso de sujeitos plenos, refletindo estudos anteriores sobre a matéria (DUARTE, 1995); porém, no último período essa tendência parece se estabilizar, com pequeno aumento no número de sujeitos nulos. 
Cadernos de ESTUDOS LINGUIISTICOS (58.2) - mai./ago. 2016

Na posição de complemento, a estratégia mais produtiva no que diz respeito à função acusativa é lhe, com 39\%, ficando a forma tradicional de acusativo o/ $a$ com $35 \%$. Isso é relevante, considerando que o uso de objetos diretos preposicionados não é comum no português europeu nem brasileiro contemporâneos. A forma dativa predominante é também o clítico lhe, com $63 \%$, ficando a forma te com meros $2 \%$. Um dado de a si foi contabilizado nessa função. Já na função de complemento oblíquo, uma preposição seguida de uma forma nominal desenvolvida foi a estratégia mais frequente. Dois dados de consigo foram identificados.

No que diz respeito à comparação entre as formas de tratamento na posição de sujeito e de complemento, notou-se que a variação se concentra nos dados de remetentes que apresentavam uso exclusivo de você na posição de sujeito. Num aspecto geral, os resultados da pesquisa corroboram um sistema de tratamento com alguns traços importantes de conservadorismo linguístico, em comparação com dados do século XVIII (MARCOTULIO, 2010) e dos séculos XIX e XX, escritos em dois outros estados do Nordeste (Pernambuco e Rio Grande do Norte; cf. MARTINS et al., 2015) e no Rio de Janeiro (LOPES \& CAVALCANTE, 2011). Aí se notam, no lado do sujeito, a inexistência de dados de $t u$ pleno e, no lado do complemento acusativo e dativo, a grande frequência da forma lhe em comparação com te, retida nessas funções gramaticais em vários outros estados.

\section{$\overline{\text { 7. REFERÊNCIAS }}$}

BROWN, R. \& GILMAN, A. (1960). The pronouns of power and solidarity. In: SEBEOK, T. A. (ed.) Style in Language. Massachussetts, MA: MIT Press, 253-276.

BROWN, L. \& LEVINSON, S. (1987). Politeness: some universal in language usage. Cambridge: Cambridge University Press.

CARNEIRO, Z. de O. N. (2005). Cartas Brasileiras (1809-1904): um estudo linguístico-filológico. Tese (Doutorado em Linguística). Campinas: Universidade Estadual de Campinas.

CARNEIRO, Z. de O. N. (Org.). (2011). Cartas Brasileiras (1809-2000): coletânea de fontes para o estudo do português. Feira de Santana: UEFS.

CARNEIRO, Z. de O. N. \& OLIVEIRA, M. F. (2016). Corpus eletrônico de documentos históricos do sertão. 2011. Disponível em: http://www.uefs.br/cedohs Acesso: 10 fev.

CARVALHO JÚNIOR, A. P. D. (2000). Cícero Dantas Martins - de barão a coronel: trajetória política de um líder conservador na Bahia. Dissertação (Mestrado em História). Salvador: Universidade Federal da Bahia.

DUARTE, M. E. L. (1995). A perda do princípio 'Evite pronome' no português brasileiro. Tese (Doutorado em Linguística). Campinas: Universidade Estadual de Campinas.

MARTINS, M. A. et al. (2015). Para um panorama sócio-diacrônico das formas de tratamento na função de sujeito na região Nordeste. LaborHistórico 1(1), 26-48.

LABOV, W. (1994). Principles of Linguistic Change: internal factors. Oxford: Blackwell. 
ANDRADE, CARNEIRO \& LACERDA - Formas tratamentais em cartas baianas: sujeito e ...

LOPES, C. R. et al. "A reorganização do sistema pronominal de 2. ${ }^{a}$ pessoa na história do português brasileiro: a posição de sujeito". Ms. UFRJ/ UEFS/ UFSC/ Unicamp/ UFRPE/ UFRN/ UFMG, 2015. [A sair em: CASTILHO, A. (org.) História do Português Brasileiro, vol. 3.]

LOPES, C. R; CAVALCANTE, S. (2011). A cronologia do voceamento no português brasileiro: expansão de você-sujeito e retenção do clítico-te. Revista Lingüistica 25, 30-65.

MARCOTULIO, L. L. (2010). Lingua e História: o 2. ${ }^{\circ}$ marquês do Lavradio e as estratégias linguísticas da escrita no Brasil Colonial. Rio de Janeiro: Ítaca Comunicações.

PHPB. Projeto para a História do Português Brasileiro. Corpus Histórico do Português. (2013). Disponível em: $<$ https://sites.google.com/site/corporaphpb> Acesso: 10 jun.

SANTIAGO, H. S. (2012). Um estudo do português popular brasileiro em cartas pessoais de mãos "cândidas" do sertão baiano. Dissertação (Mestrado em Linguística). Feira de Santana: UEFS. 